\title{
Optimization of Poly $\beta$-Hydroxy Butyrate Production by Alcaligenes Latus MTCC2311 using Central Composite Design
}

\author{
Veeramanikandan. $V$ * \\ $P G$ and Research \\ Department of \\ Microbiology \\ MGR College, Hosur, \\ Tamilnadu, India. \\ Pin - 635109
}

\author{
Mrudula. S \\ Department of \\ Microbiology \\ Palamuru university, \\ Mahabubnagar, \\ AP, India
}

\author{
Yuvaraj. R \\ $P G$ and Research \\ Department of \\ Microbiology \\ MGR College, Hosur, \\ Tamilnadu, India. \\ Pin - 635109
}

\author{
Balaji. $P$ * \\ Department of \\ Biotechnology, \\ MGR College, Hosur, \\ Tamilnadu, India. \\ Pin - 635109
}

\section{${ }^{*}$ Corresponding authors}

\begin{abstract}
Considering the industrial interest of poly-b-hydroxy butyrate (PHB) and its high production cost, work has been undertaken for the production of PHB by Alcaligenes latus (2311). Different industrial wastes (sesame, molasses, sago and paper waste) were used as a cheap substrate to minimize the production of cost and nitrogen limited minimal agar synthetic medium was also used for comparison. Accumulation of PHB granules in the organism was analyzed by sudan black method. The PHB production in various industrial waste based medium and nitrogen limited minimal agar synthetic medium was studied by crotonic acid method. The pure form of PHB was collected and qualitatively analyzed by infrared and nuclear magnetic resonance methods. Highest PHB production was found in nitrogen limited minimal agar synthetic medium. Among the various industrial wastes based media, highest yield was obtained with sesame oil waste as carbon source
\end{abstract}

\section{Keywords}

Poly- $\beta$-hydroxy butyrate, PHB, Alcaligenes latus MTCC 2311, CCD, bacterial polyesters.

\section{INTRODUCTION}

For more than seventy years petroleum based plastics have been used in a variety of industrial and day to day applications owing to their versatility and durability $[1,2]$. However, they bear negative attributes including recalcitrance to biodegradation [3] toxicity after incineration and massive waste accumulation into the landfills and the marine environment. In response to the problems associated with the synthetic polymers, the public tendency, the scientific interest and the governments determination has worked in unison over the past two decades to support the development of a new class of plastics. The challenge for the new polymers is to retain the physicochemical characteristics of the traditional plastics but benefit from biocompatibility and biodegradability $[4,5,6]$.

Polyhydroxyalkanoates (PHA) are polyesters synthesized by a variety of bacterial strains as intra cellular carbon and energy storage compounds grown usually under stress conditions [7]. As biodegradable and biocompatible materials, PHA have drawn a lot of industrial attention for the potential applications in many fields $[8,9,10,11]$. Poly (3hydroxybutyrate-co-4-hydroxybutyrate) [P(3HB-co-4HB)] was first found from Ralstonia eutropha cultivated with 4hydroxybutyric or 4-chloro butyric acid as carbon sources by Doi et al. [12]. The incorporation of 4HB units into P (3HB) improves the material application potentials, and the copolymers show a wide range of physical properties ranging from highly crystalline plastic to elastic rubber, depending on the polymer composition[13,14]. P (3HB-co-4HB) is hydrolyzed by both PHA depolymerases and lipases, and its degradation rate is relatively rapid compared with other PHA. Thus, $\mathrm{P}(3 \mathrm{HB}-\mathrm{co}-4 \mathrm{HB})$ with various $4 \mathrm{HB}$ compositions are promising materials that have favorable biodegradability and mechanical properties. $\mathrm{P}$ (3HB-co-4HB) has been produced in a few bacteria, including $R$. eutropha, Alcaligenes latus [15,16,17,18], Comamonas acidovorans [19,20], Comamonas testosteronii [21] and Hydrogenophaga pseudoflava [22]. Generally, carbon sources structurally related to $4 \mathrm{HB}$ are required to generate 4HB-containing PHA, such as 4-hydroxy butyric acid, g-butyrolactone and1,4-butanediol [23,24,25,26]. However, these carbon sources are much more expensive than glucose or other 3HB-generating carbon sources are for example, 4-hydroxy butyric acid is considered to be the most effective precursor for forming $4 \mathrm{HB}$ monomer, but it is difficult to obtain since 4-hydroxy butyric acid is a controlled substance in countries like USA and China. The high cost of raw material for the co-polymer production has become an obstacle for the wide production and application of $\mathrm{P}(3 \mathrm{HB}-\mathrm{co}-$ 4HB).

Biological waste water treatment technology has been extensively applied to treat both municipal sewage and industrial waste water. However, the active microorganisms may be exposed to alternating feast and famine conditions due to the fluctuations in the hydraulic loading and nutrient concentrations of the waste water treatment plants [27]. It has been reported that, after heavy rainfall or on weekends, a municipal waste water treatment plant (WWTP) can temporarily receive low concentrations of sewage and a high hydraulic loading, which could lead to the active microorganisms suffering famine periods for hours [28]. As for the industrial waste water (e.g. the dairy and food processing industries, paper mills and abattoirs), the WWTPs may be more prone to suffering large fluctuations in the waste water composition and flow, and even complete interruptions of waste water flows due to the nature of the industrial activities[29,30]. Therefore, the biomass may be in famine periods for hours, and even for days or weeks. Such famine periods can significantly affect the amount and activity of 
active microorganisms and performance of a waste water treatment system $[31,32,33,34]$. Therefore, the ability of the biomass to survive under such conditions needs to be investigated in order to achieve reliable biological waste water treatment [35].

The British Chemical giant, Imperial Chemical Industries (ICI) began investigating in 1976; the possibility of producing PHB from carbohydrate feed stocks. The use of renewable substrates added to the biological advantages of producing PHB, but the project slowed down, mainly because of high cost of production and insufficient demand [36,37]. The process has been, however, revived many years later and now Alcaligenes eutrophus and Alcaligenes latus are currently utilized and commercially produced under the trade name Biopol by Monsanto, which acquired the business from Zeneca bioproducts, an offshoot of ICI [38].

\section{MATERIALS AND METHODS}

\subsection{Organism}

Alcaligenes latus MTCC2311 was obtained from the Microbial type culture collection, Chandigarh, India. The PHB producing capability of the organism was confirmed by Sudan black staining method [39].

\subsection{Central Composite Design and Response Surface Methodology}

The levels of the significant parameters and interaction effects between four industrial waste and the bacterial strain viz., Alcaligenes eutrophus was used for the production of PHB were analyzed and optimized by using a central composite design in response surface methodology. The experimental design was carried out by using "Stat-Ease Design-Expert" software (version 8.1, Stat-Ease Corporation, USA). The four independent factors were investigated at five different levels $(-2,-1,0,+1,+2)$. The response Y (yield of PHB) was analyzed by using a second order polynomial equation in four independent variables and the data were fitted into the equation by multiple regression procedure.

The model equation for analysis is given below Eq.

$$
\mathrm{Y}=\beta_{0}+\Sigma \beta_{\mathrm{i}} \mathrm{X}_{\mathrm{i}}+\Sigma \beta_{\mathrm{ii}} \mathrm{X}^{2}{ }_{\mathrm{i}}+\Sigma \beta_{\mathrm{ij}} \mathrm{X}_{\mathrm{i}} \mathrm{X}_{\mathrm{j}}
$$

where $\mathrm{Y}$ is the predicted response, $\mathrm{X}_{\mathrm{i}}, \mathrm{X}_{\mathrm{j}}$ represent the independent variables which influence the response variable $\mathrm{Y}$, and $\beta_{0}, \beta_{\mathrm{i}}, B_{\mathrm{ii}}$, and $\beta_{\mathrm{ij}}$ represent the offset term, the ith linear coefficient, the ith quadratic coefficient and the interaction coefficient, respectively. "Design-Expert" 8.1 was used for regression and graphical analyses of the data obtained. Statistical analysis of the model was performed to evaluate the analysis of variance (ANOVA). The student's t-test permitted the checking of the statistical significance of the regression coefficient, and the Fischer's test determined the second-order model equation. The quality of the fit of the polynomial model equation was given by the coefficient of determination (R2). The optimum concentration of the variables were calculated from the data obtained by using the response surface regression procedure of the SAS statistical package (Version 8.1, SAS institute inc. NC. USA).

\subsection{PHB production and extraction}

Four different industrial waste substrates such as (seasame, molasses, sago and paper waste) were collected from industries and were used for the PHB production in different percentage $(10,20,30,40$ and $50 \%)$. The PHB production by
A. latus on different industrial wastes [40] under aerobic conditions was studied. A. latus was grown at $37^{\circ} \mathrm{C}$ for $72 \mathrm{~h}$. PHB produced were extracted as described in the method of Ramsay et al.[41,42].

\subsection{Estimation and qualitative analysis of PHB}

The amount of PHB in the extracted samples was determined spectrophotomertrically at $235 \mathrm{~nm}[43,44]$. The pure form PHB was collected [45] and qualitatively analyzed by infrared method [46] and by NMR method [47].

\section{RESULTS AND DISCUSSION}

\subsection{Central Composite Design and Response Surface Methodology}

Central Composite Design is powerful method for screening significant factor in the presence study, 30 runs were carried out to investigate the production optimization of PHB using four different factors viz., seasame oil waste, sago waste, molasses waste and paper waste. The PHB production varied from 1.96 grams/litre to 3.21 grams/litre in industrial waste used for the study. Response surface methodology help in evaluation of relationship between the dependent (PHB yielded) variable and independent variables and predicted values of the PHB production are shown. The accuracy of the model can be seen by the different between observed and predicted value. The co-efficient and the analysis of variance are presented in table. Fitness of the model was expected by the value of the determination co-efficient in the present PHB comes out to be 1.95 for PHB production high value of adjust co-efficient determination this adjusted 3.21 indicate high significance of model (Fig. 1 and Fig. 6).

\subsection{FTIR spectrum}

Figure 7 shows the FTIR spectrum of the extracted polymer isolated in the study. The FT-IR spectrums obtained were compared with the spectrum of commercially available PHB. The large absorption peak at $3395.07 \mathrm{~cm}^{-1}-3452.34 \mathrm{~cm}^{-1}$ was OH stretching and C-H was between $2924.25 \mathrm{~cm}^{-1}-2994.59$ $\mathrm{cm}^{-1}$. The absorption band at $1723.45 \mathrm{~cm}^{-1}-1728.87 \mathrm{~cm}^{-1}$ attributed to the stretching vibration of the carboxyl bond $(\mathrm{C}=\mathrm{O})$. The band at $2321.87 \mathrm{~cm}^{-1}-2359.02 \mathrm{~cm}^{-1}$ was assigned to the $\mathrm{C} \equiv \mathrm{C}$ stretching of alkynes. Absorption peaks between $1537.95 \mathrm{~cm}^{-1}$ and $1655.59 \mathrm{~cm}^{-1}$ indicates the presence of nitro compounds. The bands between $1547.59 \mathrm{~cm}^{-1}$ and 1597.11 $\mathrm{cm}^{-1}$ arise from N-H vibration of amines. Intense bands centered at $1078.01 \mathrm{~cm}^{-1}-1283.39 \mathrm{~cm}^{-1}$ were assigned to $\mathrm{C}-\mathrm{N}$ vibrations of amine group. The obtained IR absorption peaks correlated with the literature value and with the spectrum of pure PHB. From the above details it is concluded that the compound should be PHB.

\section{6. ${ }^{1} \mathrm{H}$ NMR spectral analysis}

The obtained spectrum for the Alcaligenes latus PHB showed the following results (Figure 8). The NMR spectra identified the polymer as an isocratic homopolymer. The spectrum revealed the presence of three group of signals characteristic of PHB homopolymer. The doublet at $1.25 \mathrm{ppm}$ was attributed to the methyl group coupled to one proton; the doublet of the quadruplet around $2.5 \mathrm{ppm}$ to the methylene group adjacent to an asymmetric carbon atom bearing a single proton and the singlet at $5.6 \mathrm{ppm}$ to the methyne group. Chloroform-d gave a chemical shift signal at $7.26 \mathrm{ppm}$.

\section{CONCLUSION}

RSM was used to estimate and optimize the PHB production. All the independent variables, quadratic of all the independent 
variables had highly significant effects on the response values $(\mathrm{p}<0.03)$. The optimal media composition for PHB production was obtained through a central composite design in response surface methodology as 1.96 to 3.21. Under these conditions, the experimental yield of PHB was 3.21 gms in the factor with preliminary media optimization experiments with the use of industrial wastes (Table 1).

\section{REFERENCES}

[1] Ojumu TV, Yu J, Solomon BO: Production of Polyhydroxyalkanoates, a bacterial biodegradable polymer. Afr J Biotechnol 2004, 43:18-24.

[2] Zinn M, Witholtb B, Eglia T: Occurrence, synthesis and medical application of bacterial polyhydroxyalkanoate. Adv Drug Deliv Rev 2001, 53:5-21

[3] Reddy CSK, Ghai R, Rashmi, Kalia VC: Polyhydroxyalkanoates: an overview. Bioresour Technol 2003, 87:137-146

[4] Lee SY: Bacterial polyhydroxyalkanoates. Biotechnol Bioeng 1996, 49:1-14.

[5] Amass W, Amass A, Tighe B: A review of biodegradable polymers: use, current developments in the synthesis and characterization of biodegradable polyesters, blends of biodegradable polymers and recent advances in biodegradable studies. Polym Int 1998, 47:89-144.

[6] Muller R-J, Kleeberg I, Deckwer W-D: Biodegradation of polyesters containing aromatic constituents. J Biotechnol 2001, 86:87-95.

[7] Anderson AJ, Dawes EA. Occurrence, metabolism, metabolic role, and industrial uses of bacterial polyhydroxyalkanoates. Microbiol Mol Biol Rev. 1990; 54 (4): 450-472

[8] Martin DP, Williams SF. Medical applications of poly-4hydroxybutyrate: a strong flexible absorbable biomaterial. Biochem Eng J 2003;16:97-105

[9] Park, S.J.,Choi,J.I.,Lee,S.Y.,2005b.Short-chainlengthpolyhydroxyalkanoates: Synthesis inmetabolicallyengineered Escherichia coli and medicalapplica- tions. J.Microbiol.Biotechnol.15,206215

[10] Hazer, B., Steinbuchel, A., 2007. Increased diversification of polyhydroxyalkanoates by modification reactions for industrial and medical applications. Appl. Microbiol. Biotechnol. 74, 1-12.

[11] Chen, G.Q., 2009. A microbial polyhydroxyalkanoates (PHA) based bio- and materials industry. Chem. Soc. Rev. 38, 2434-2446.

[12] Doi, Y., Kunioka, M., Nakamura, Y., Soga, K., 1988. Nuclear magnetic-resonance studies on unusual bacterial copolyesters of 3-hydroxybutyrate and 4hydroxybutyrate. Macromolecules 21, 2722-2727

[13] Saito,Y.,Nakamura,S.,Hiramitsu,M.,Doi,Y.,1996.Microbi alsynthesisand properties of poly (3-hydroxybutyrate-co4-hydroxybutyrate). Polym.Int.39, 169-174

[14] Ishida,K.,Wang,Y.,Inoue,Y.,2001.Comonomerunitcompo sitionandthermal properties ofpoly(3-hydroxybutyrateco-4-hydroxybutyrate)s biosynthesized by Ralstonia eutropha. Biomacromolecules2,1285-1293.
[15] Kunioka,M.,Kawaguchi,Y.,Doi,Y.,1989.Productionofbio degradablecopolye- sters of3-hydroxybutyrateand4hydroxybutyrateby Alcaligenes eutrophus. Appl. Microbiol.Biotechnol.30,569-573

[16] Valentin HE, Stuart ES, Fuller RC, Lenz RW and Dennis D. 1998. Investigation of the function of protein associated to polyhyroxyalkanoate inclusion in Pseudomonas putida BMO1. J Biotechnol. 63(2-3):14557

[17] Saito,Y.,Nakamura,S.,Hiramitsu,M.,Doi,Y.,1996.Microbi alsynthesisand properties ofpoly(3-hydroxybutyrate-co4-hydroxybutyrate). Polym.Int.39, 169-174

[18] Ishida,K.,Inoue,Y.,2004.Modaldifferenceincomonomerunitcompositional distributions ofpoly(3hydroxybutyrate-co-4-hydroxybutyrate)s biosynthesized bytwostrains, Ralstonia eutropha and Alcaligenes latus. Biomacromole- cules 5,1135-1140.

[19] Mitomo,H.,Hsieh,W.C.,Nishiwaki,K.,Kasuya,K.,Doi,Y., 2001.Poly (3-hydroxybutyrate-co-4-hydroxybutyrate) producedby Comamonas acido- vorans. Polymer42,3455-3461

[20] Lee,W.H.,Azizan,M.N.M.,Sudesh,K.,2004.Effectsofcultu reconditionsonthe composition ofpoly(3hydroxybutyrate-co-4-hydroxybutyrate) synthesized by Comamonas acidovorans. Polym.Degrad.Stabil.84,129134

[21] Renner, G. et al. (1996) Production of poly(3hydroxybutyrate-co-4- hydroxybutyrate) by Comamonas testosteronii A3. Food Technol. Biotechnol. 34, 91-95

[22] Choi, M.H. et al. (1999) Production of poly(3hydroxybutyric acid-co-4- hydroxybutyric acid) and poly(4-hydroxybutyric acid) without subsequent degradation by Hydrogenophaga pseudoflava. Appl. Environ. Microbiol. 65, 1570- 1577

[23] Kunioka,M.,Kawaguchi,Y.,Doi,Y.,1989.Productionofbio degradablecopolye- sters of3-hydroxybutyrateand4hydroxybutyrateby Alcaligenes eutrophus. Appl. Microbiol.Biotechnol.30,569-573

[24] Mitomo,H.,Hsieh,W.C.,Nishiwaki,K.,Kasuya,K.,Doi,Y., 2001.Poly (3-hydroxybutyrate-co-4-hydroxybutyrate) producedby Comamonas acido- vorans. Polymer42,3455-3461

[25] Lee,W.H.,Azizan,M.N.M.,Sudesh,K.,2004.Effectsofcultu reconditionsonthe composition ofpoly(3hydroxybutyrate-co-4-hydroxybutyrate) synthesized by Comamonas acidovorans. Polym.Degrad.Stabil.84,129134

[26] Kim, J.S., Lee, B.H., Kim, B.S., 2005. Production of poly(3-hydroxybutyrate-co-4- hydroxybutyrate) by Ralstonia eutropha. Biochem. Eng. J. 23, 169-174

[27] Lu, H.B., Keller, J., Yuan, Z.G., 2007. Endogenous metabolism of Candidatus Accumulibacter phosphatis under various starvation conditions. Water Res. 41, 4646-4656

[28] Brdjanovic, D., Slamet, A., van Loosdrecht, M.C.M., Hooijmans, C.M., Alaerts, G.J., Heijnen, J.J., 1998. Impact of excessive aeration on biological phosphorus removal from waste water. Water Res. 32 (1), 200-208. 
[29] Yilmaz, G., Lemaire, R., Keller, J., Yuan, Z., 2007. Effectiveness of an alternating aerobic, anoxic/anaerobic strategy for maintaining biomass activity of BNR sludge during long-term starvation. Water Res. 41 (12), 25902598

[30] Pijuan, M., Werner, U., Yuan, Z.G., 2009. Effect of long term anaerobic and intermittent anaerobic/aerobic starvation on aerobic granules. Water Res. 43, 36223632

[31] van Loosdrecht, M.C.M., Henze, M., 1999. Maintenance, endogeneous respiration, lysis, decay and predation. Water Sci. Technol. 39 (1), 107-117

[32] Lopez, C., Pons, M.N., Morgenroth, E., 2006. Endogenous processes during long-term starvation in activated sludge performing enhanced biological phosphorus removal. Water Res. 40 (8), 1519-1530

[33] Lu, H.B., Keller, J., Yuan, Z.G., 2007. Endogenous metabolism of Candidatus Accumulibacter phosphatis under various starvation conditions. Water Res. 41, $4646-4656$

[34] Wang, Y.Y., Geng, J.J., Ren, Z.J., He, W.T., Xing, M.Y., Wu, M., Chen, S.W., 2011. Effect of anaerobic reaction time on denitrifying phosphorus removal and $\mathrm{N}_{2} \mathrm{O}$ production. Bioresour. Technol. 102, 5674-5684

[35] Pijuan, M., Werner, U., Yuan, Z.G., 2009. Effect of long term anaerobic and intermittent anaerobic/aerobic starvation on aerobic granules. Water Res. 43, 36223632

[36] Braunegg, G, Lefebvre, G. and Genser, K. F. (1998) Polyhydroxyalkanoates, biopolyesters from renewable resources: physiological and engineering aspects. J.Biotechnol. 65; 127-61.

[37] Lee, S. Y and Chang, H. N. (1995). Production of poly (hydroxy alkanoic acid) Adv.Biochem.Eng.Biotechnol. $52 ; 27-58$.
[38] Feischter, A. (1990). Plastics from bacteria and for bacteria: Poly ( $B$ hydroxy alkanoates) as natural, biocompatible and biodegradable polyesters. Springerverlag, New York, pp, 77-93

[39] Kitamura S, Doi Y (1994). Staining method of poly (3hydroxyalkanotes acids) producing bacterial by nile blue. Biotechnol. Techniques 8:345-350

[40] Lee SY, Choi J (1999). Polyhydroxyalkanoate: biodegradable polymer. In Manual of Industrial Microbiology and Biotechnology, 2 edn. Edited by Demain AL., Deavies JE, Washington DC:ASM:616627.

[41] Ramsay, J. A, Berger, E, Ramsay, B. A. and Chavarie, C. (1994a). Recovery of poly-3-hydeoxyalkanoic acid granules by a surfactant - hypochlorite treatment. Biotechnol.Techning 9(10); 709-712.

[42] Ramsay, Berger, E, Chaverie, C. and Ramsay, B. A. (1994b). Extraction of poly- 3-hydroxybutyrate using chlorinated solvents. Biotechnol.Techniques 8:589-594.

[43] Lee IY, Chang HN, Park YH (1995). A simple method for recovery of microbial poly - $\beta$ - hydroxybutrate by alkaline solution treatment.J.Microbial.Biotechnol.5:238240

[44] Law, Ralph, A. Slepecky (1960). Asay of poly bhydroxyl butyric acid. J.Bacterioloty. 82:33-36.

[45] Lee, S. Y., 1996, Bacterial Polyhydroxyalkanoates. Biotechnology and Bioengineering, 49:1-14.

[46] Silverstein, Bassler, Morril (1981). Spectrometric identification of organic compounds. John wiley and Sons 4th Edn.

[47] Bernard N, KM Sandrs (1989). The poly Hydroxy butyrate granules in vivo. J. Biol. Chem. 264:3286-3292 
Figure 1. - PHB Model Graph of Alcaligenes latus MTCC 2311 in Sago and seasame oil waste

Design-Expert@ Software Factor Coding : Actual PHB Production

$\prod_{1.96}^{3.21}$

$\mathrm{X} 1=\mathrm{A}:$ Sago waste

X2 $=\mathrm{B}$ : Seasame

Actual Factors

C: Molasses $=-1.95$
D: Paper waste $=0.38$

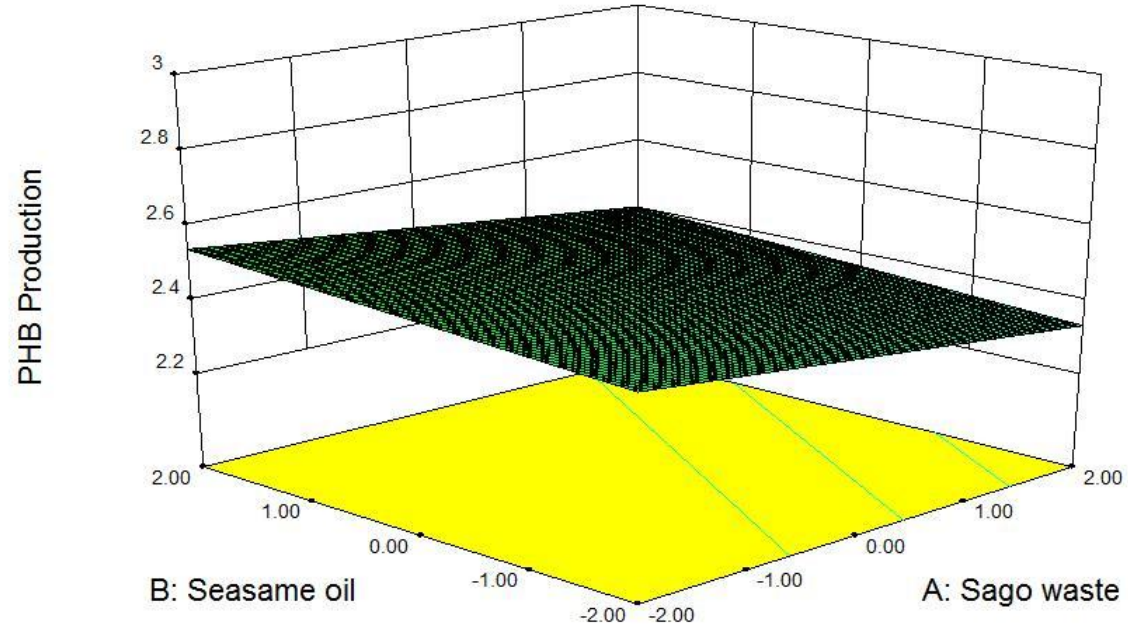

Figure 2. - PHB Model Graph of Alcaligenes latus MTCC 2311 in Sago and molasses waste

Design-Expert(8) Software Factor Coding: Actual Productir

1.21

$\mathrm{X} 1=\mathrm{A}:$ Sago waste $\mathrm{X} 2=\mathrm{C}:$ Molasses

Actual Factors

B: Seasame oil $=0.00$

D: Paper waste $=0.38$

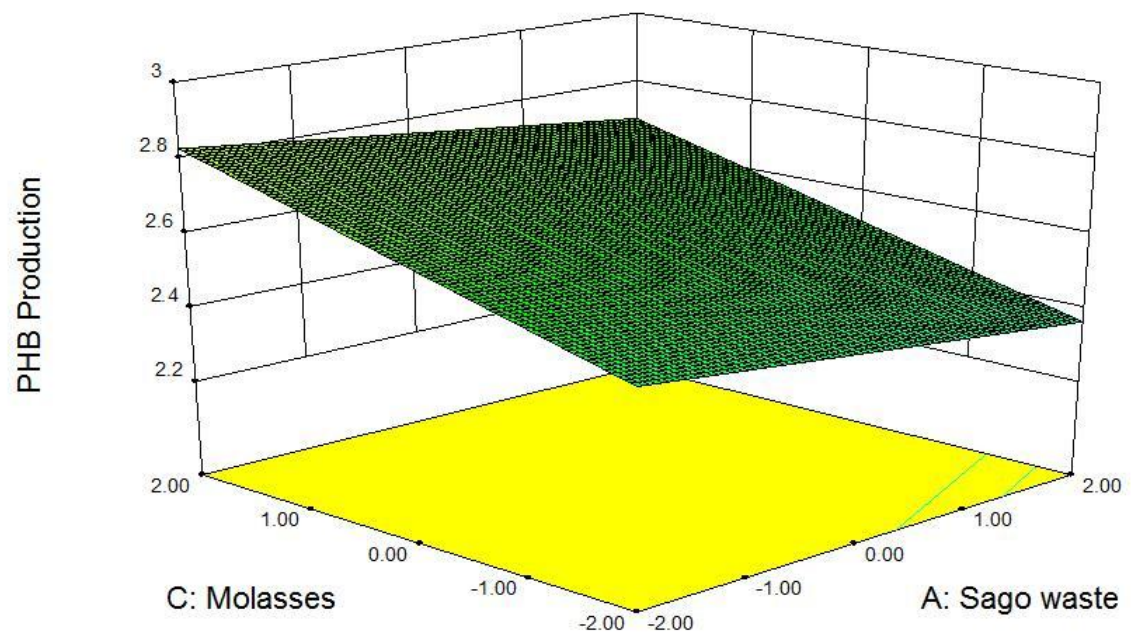


Figure 3. PHB Model Graph of Alcaligenes latus MTCC 2311 in Sago and paper waste

Design-Expert@ Software
Factor Coding: Actual

PHB Production

$\coprod_{1.96}^{3.21}$

$\mathrm{X}_{1}=\mathrm{A}$ : Sago waste

Actual Factors

B. Seasame oil $=0.00$

C: Molasses $=-1.95$
X2 = D: Paper waste

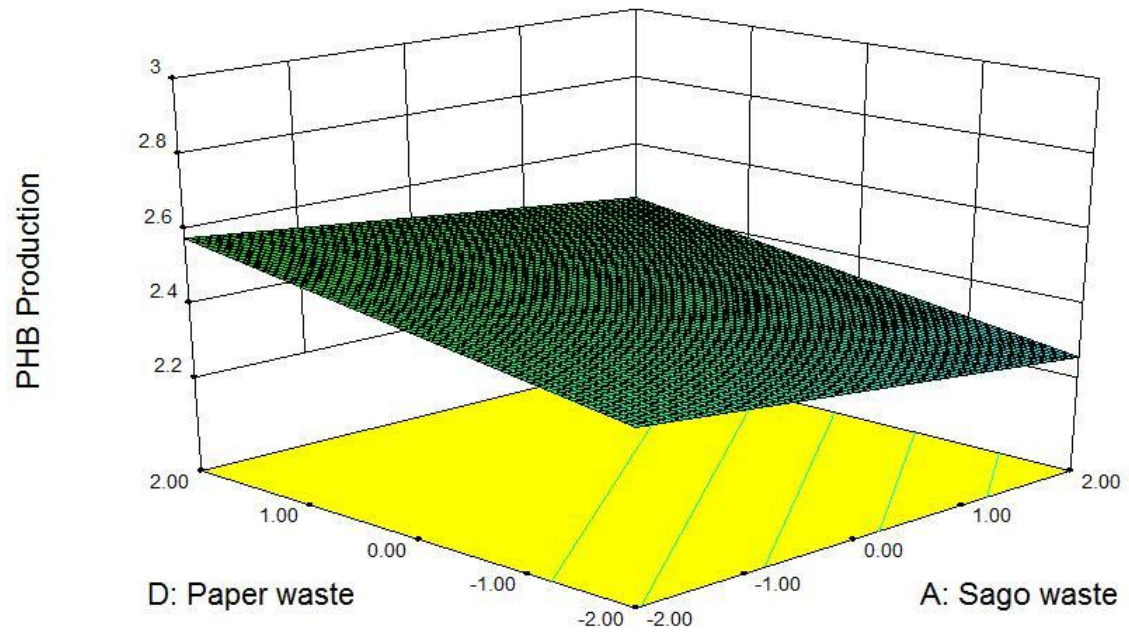

Figure 4. PHB Model Graph of Alcaligenes latus MTCC 2311 in Seasame oil and molasses waste

Design-Expert@ Software

Factor Coding: Actua

3.21
1.96

$\mathrm{X} 1=\mathrm{B}$ : Seasame oil

$\mathrm{X} 2=\mathrm{C}:$ Molasses

Actual Factors

A: Sago waste $=0.00$

er waste $=-1.08$

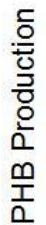

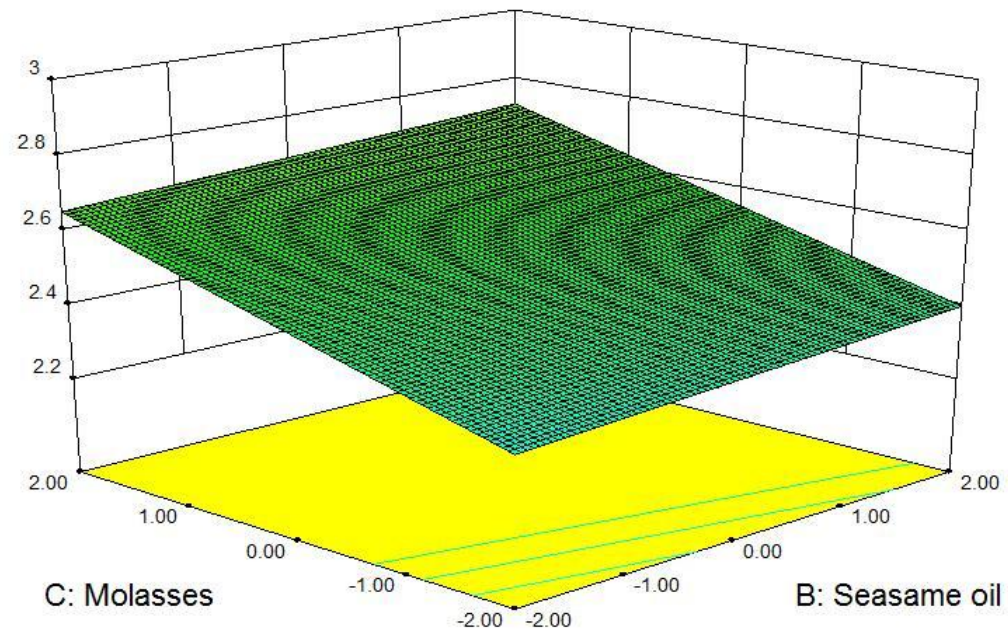


Figure 5. PHB Model Graph of Alcaligenes latus MTCC 2311 in Seasame oil and paper waste

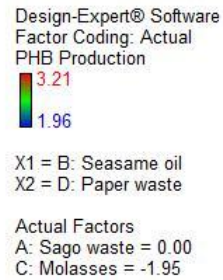

1.96

$\mathrm{X} 1=\mathrm{B}$ : Seasame oil $\mathrm{X} 2=\mathrm{D}$ : Paper waste

Actual Factors

A. Sago waste $=0.00$

Molasses $=-1.95$

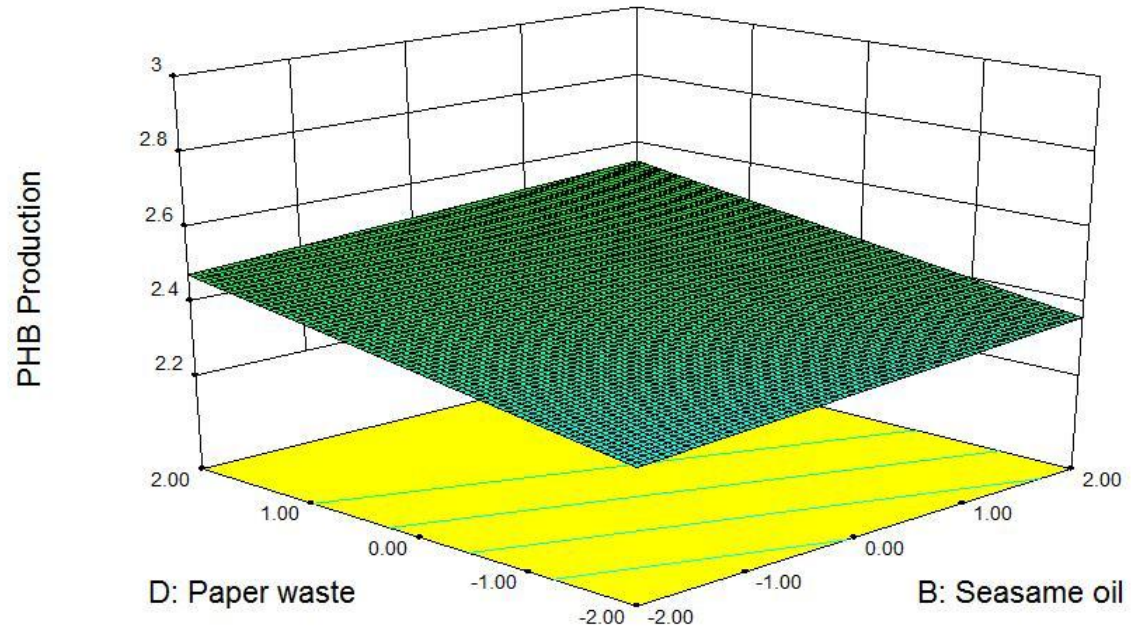

Figure 6. PHB Model Graph of Alcaligenes latus MTCC 2311 in Molasses and paper waste

Design-Expert@ Software Factor Coding: Actual $\pi^{3} 21$

1.96

$\mathrm{X} 1=\mathrm{C}:$ Molasses $\mathrm{X} 2=\mathrm{D}:$ Paper waste

Actual Factors

A: Sago waste $=0.00$
B: Seasame oil $=-0.76$

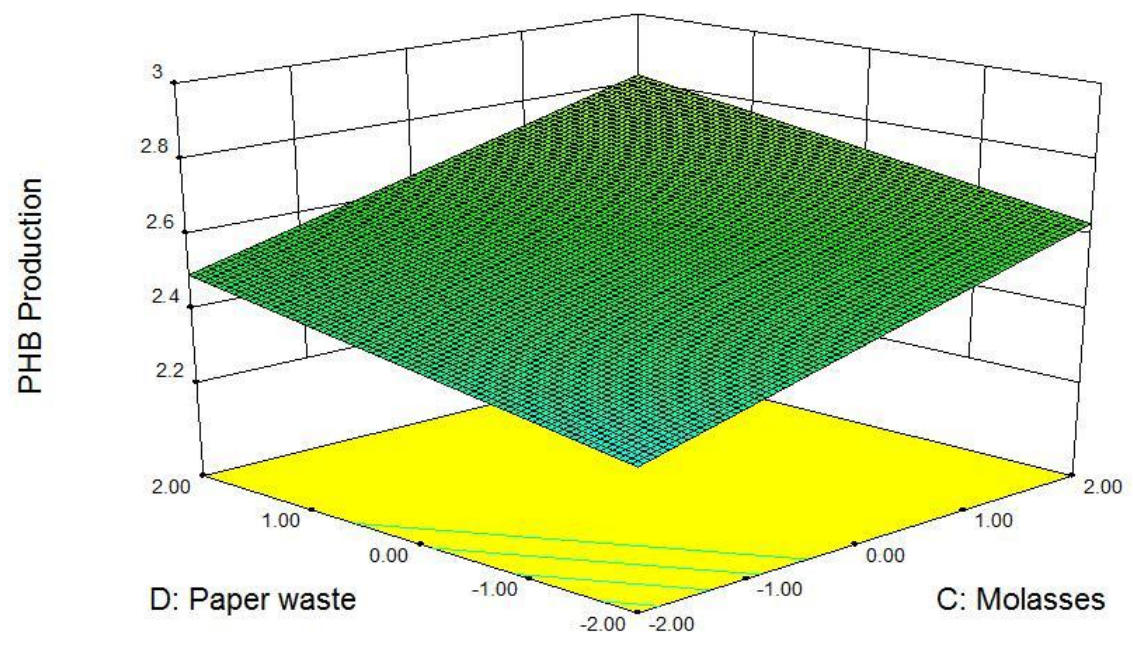


Figure 7. FTIR Spectrum of PHB produced by Alcaligenes latus MTCC 2311

由 SHIMADZu

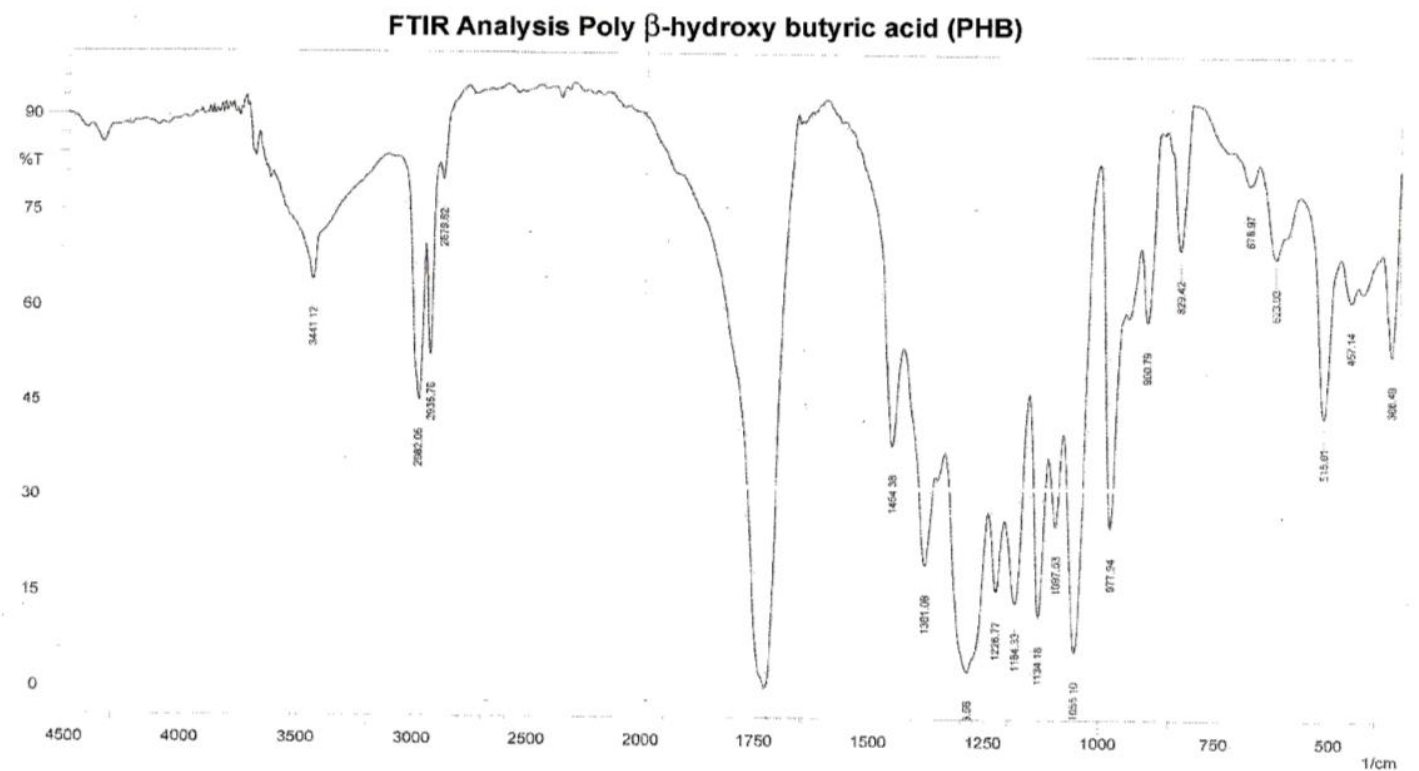

Figure 8. ${ }^{1} \mathrm{H}$ NMR Spectrum of PHB produced by Alcaligenes latus MTCC 2311

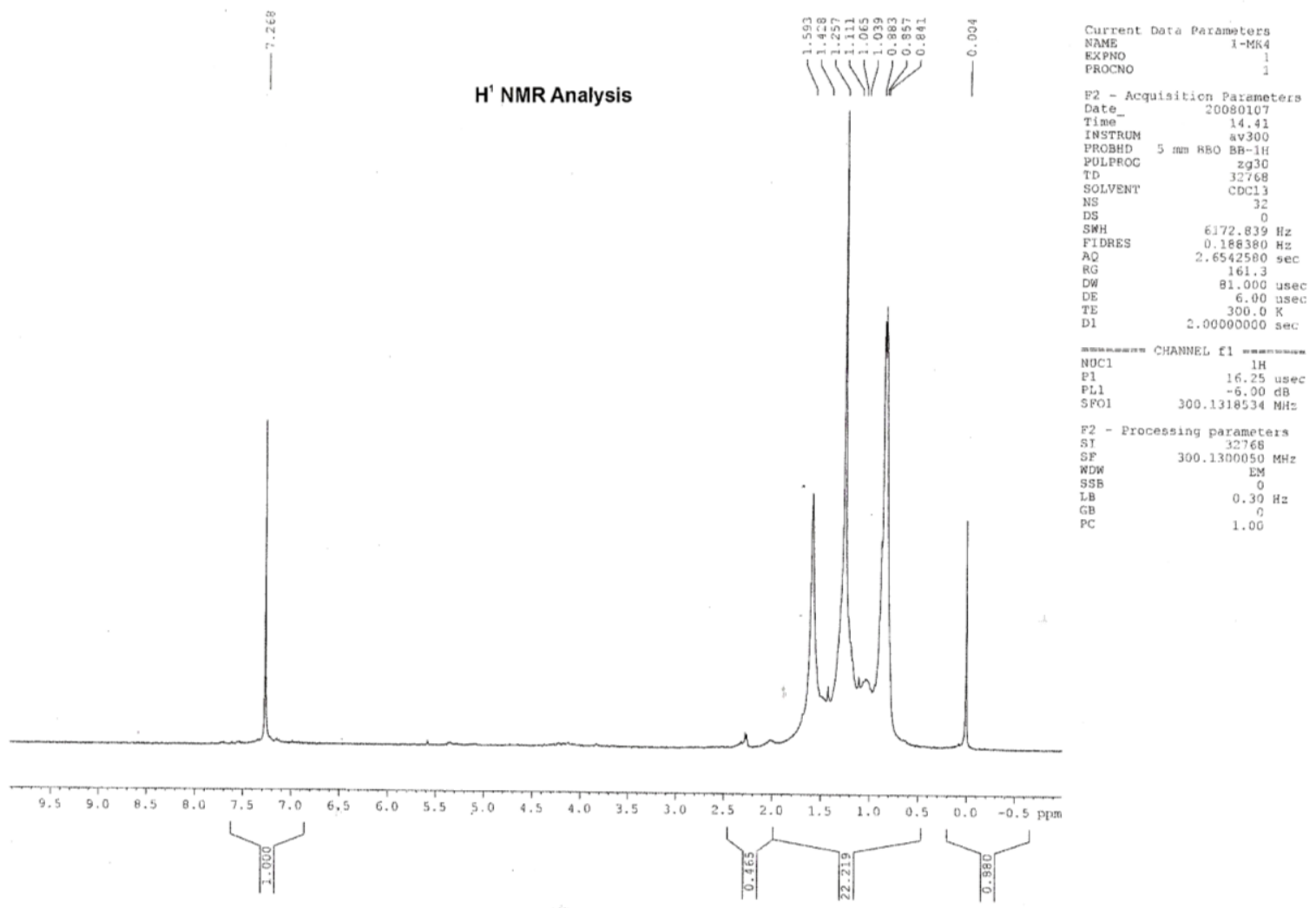


Table 1. Response surface methodology yield of PHB by Alcaligenes latus MTCC 2311

\begin{tabular}{|c|c|c|c|c|c|c|}
\hline Run & Trial & $\begin{array}{c}\text { Sago } \\
\text { waste }\end{array}$ & $\begin{array}{c}\text { Seasame } \\
\text { oil }\end{array}$ & Molasses & $\begin{array}{l}\text { Paper } \\
\text { waste }\end{array}$ & $\begin{array}{c}\text { PHB } \\
\text { production } \\
\text { (g/litre) }\end{array}$ \\
\hline 14 & 1 & 2 & -2 & 2 & 2 & 2.17 \\
\hline 12 & 2 & 2 & 2 & -2 & 2 & 2.17 \\
\hline 23 & 3 & 0 & 0 & 0 & -4 & 2.25 \\
\hline 18 & 4 & 4 & 0 & 0 & 0 & 2.25 \\
\hline 7 & 5 & -2 & 2 & 2 & -2 & 2.17 \\
\hline 1 & 6 & -2 & -2 & -2 & -2 & 2.17 \\
\hline 4 & 7 & 2 & 2 & -2 & -2 & 2.17 \\
\hline 6 & 8 & 2 & -2 & 2 & -2 & 3.04 \\
\hline 21 & 9 & 0 & 0 & -4 & 0 & 2.25 \\
\hline 16 & 10 & 2 & 2 & 2 & 2 & 3.21 \\
\hline 25 & 11 & 0 & 0 & 0 & 0 & 2.25 \\
\hline 11 & 12 & -2 & 2 & -2 & 2 & 2.32 \\
\hline 13 & 13 & -2 & -2 & 2 & 2 & 2.52 \\
\hline 26 & 14 & 0 & 0 & 0 & 0 & 2.76 \\
\hline 20 & 15 & 0 & 4 & 0 & 0 & 3.21 \\
\hline 10 & 16 & 2 & -2 & -2 & 2 & 3.04 \\
\hline 15 & 17 & -2 & 2 & 2 & 2 & 3.1 \\
\hline 3 & 18 & -2 & 2 & -2 & -2 & 3 \\
\hline 19 & 19 & 0 & -4 & 0 & 0 & 3 \\
\hline 5 & 20 & -2 & -2 & 2 & -2 & 3 \\
\hline 24 & 21 & 0 & 0 & 0 & 4 & 3 \\
\hline 30 & 22 & 0 & 0 & 0 & 0 & 3 \\
\hline 2 & 23 & 2 & -2 & -2 & -2 & 1.96 \\
\hline 29 & 24 & 0 & 0 & 0 & 0 & 2.28 \\
\hline 17 & 25 & -4 & 0 & 0 & 0 & 2.91 \\
\hline 8 & 26 & 2 & 2 & 2 & -2 & 2.4 \\
\hline 22 & 27 & 0 & 0 & 4 & 0 & 2.92 \\
\hline 9 & 28 & -2 & -2 & -2 & 2 & 2.17 \\
\hline 28 & 29 & 0 & 0 & 0 & 0 & 2.25 \\
\hline 27 & 30 & 0 & 0 & 0 & 0 & 2.43 \\
\hline
\end{tabular}

